\title{
A modernidade: uma nova (era) cultura axial?'
}

Wolfgang Schluchter ${ }^{2}$

\section{Resumo}

A proposição de uma era axial, durando aproximadamente entre 800 e 200 a.C. e ocorrendo nas principais civilizações do mundo antigo (China, Índia e Oriente Próximo), independentes umas das outras, foi primeiramente introduzida por Alfred Weber e Karl Jaspers. Posteriormente ela foi desenvolvida por Robert Bellah e Shmuel Eisenstadt, entre outros, e procurava entender desde o início se teria havido uma segunda era axial que nos conduziu à modernidade e, em caso afirmativo, se ela consiste em uma secularização das conquistas da primeira era axial. Neste artigo argumenta-se que a noção de segunda era axial é significativa, mas que a emergência da modernidade não pode ser explicada em termos de secularização das realizações da primeira era axial. Ao invés, institucionalizou-se um novo princípio axial que separa o mundo moderno do pré-moderno. Esse novo princípio é enunciado com referência a Hans Blumenberg, Charles Taylor e, sobretudo, Max Weber. A ênfase encontra-se na dialética do desencantamento e no lugar da religião em uma era secular.

Palavras-chave: Primeiro e segundo princípio axial. Dialética do desencantamento. Religião em uma era secular.

\section{Introdução}

No final de sua vida, o sociólogo americano Robert Bellah (2011) nos apresentou um luminoso estudo intitulado: Religion in Human Evolution. Podemos ler este estudo como a solução para problemas com os quais ele já vinha trabalhado desde o início de sua obra. Em 1963, na Universidade de Harvard, juntamente com Talcott Parsons e Shmuel N. Eisenstadt, ele já discutia o problema da evoluçấo das religiōes. Resultou daí o texto "Religious Evolution", mais tarde publicado na sua influente coletânea de escritos intitulada Beyond

\footnotetext{
Tradução de Carlos Eduardo Sell.

2 Doutor em Sociologia pela Universidade Livre de Berlim, com livre docência na Universidade de Mannheim. É professor emérito do Instituto Max Weber de Sociologia da Universidade de Heidelberg.
} 
Belief (BELLAH, 1970). Este texto foi profundamente influenciado pelos argumentos de Clifford Geertz e de Max Weber. Partindo de Geertz (1973, p. 87 ss), ele formulou sua definiçãao de religião ou simbolismo religioso e partindo de Max Weber (1920, p. 387 ss) retomou a ideia de que, no curso da evolução religiosa, é possível perceber uma transição da afirmação do mundo para a negação do mundo, isto é, para sua rejeição religiosamente motivada. ${ }^{4}$ Sua argumentação está baseada em dois pressupostos (que ele chamada de fatos): 1) No primeiro milênio antes de Cristo, em diferentes culturas do mundo antigo, e de forma quase simultânea, assistimos ao surgimento do fenômeno da rejeição do mundo, cuja consequência é uma “[...] avaliação extremamente negativa do homem e da sociedade e a exaltação de outra esfera da realidade como a única verdadeira e infinitamente valiosa" (BELLAH, 1970 , p. 22). Esta rejeição do mundo ainda não existia nas religiôes anteriores e também desapareceu do mundo moderno (BELLAH, 1970, p. 23).

Neste artigo, Bellah (1970) diferencia cinco estágios na evolução das religiôes: o primitivo, o arcaico, o histórico, o pré-moderno e o moderno. Mas o corte decisivo está na transição do estágio arcaico para o histórico, pois é nele que se desenvolveu uma imagem dualista do mundo - no qual há uma nítida diferença entre o imanente e o transcendente e no qual este último possui a prioridade em relação ao primeiro. Nas culturas do mundo antigo essa ruptura radical conseguiu institucionalizar-se de forma duradoura, mas na transição do estágio histórico para o estágio pré-moderno esse cenário começou a mudar. Portanto, ainda que possamos encontrar movimentos similares em todas as religióes, o fato é que apenas o cristianismo conseguiu adaptar-se ao estágio moderno. Para que isso fosse possível, Bellah acentua especialmente o significado global da Reforma que, para tomar emprestado uma expressão de Ernst Troeltsch, nos levou para uma era confessional. Apenas ela pôde institucionalizar permanentemente a relação direta entre o indivíduo e a realidade transcendental: "A Reforma Protestante é a única tentativa que foi institucionalizada com sucesso", afirma Bellah (1970, p. 36). Mesmo assim, o autor coloca em dúvida se este estágio pré-moderno realmente se diferencia dos demais, pois pode ser que se trate apenas de uma fase de transição. Por outro

30 artigo foi publicado primeiramente na American Sociological Review em 1964.

4 Também em Max Weber-Gesamtausgabe, I/I9, p. 479ss. (MWG I/19). 
lado, ele está plenamente seguro do total colapso da dualidade (transcendente $\mathrm{x}$ imanente) no mundo moderno. Em nossa época, não existe mais espaço "para um sistema religioso dualista hierárquico do tipo histórico clássico" (BELLAH, 1970, p. 40).

Bellah observa, contudo, que a superação deste dualismo (base das religiôes históricas) não significa, de forma nenhuma, qualquer possibilidade de retorno ao monismo primitivo. No estágio moderno, a posição pós-dualista das religióes necessita de redefinição. Ao mesmo tempo, a modernidade também não é puramente secular, porquanto "[...] a análise do homem moderno como secular, materialista, desumanizado e, no sentido mais profundo, arreligioso, parece-me fundamentalmente equivocada, pois esse entendimento se baseia em padróes que não podem aferir adequadamente a índole moderna" (BELLAH, 1970).

Lendo seu livro mais recente à luz deste artigo (que é bem mais antigo), chama a atenção seu profundo mergulho no passado. $\mathrm{O}$ livro de Bellah não discute o presente, mas nos leva até os primórdios da humanidade. Seu interesse está centrado na pré-história da era axial, bem como em seu significado. Portanto, é o conceito de era axial, termo primeiramente sugerido por Alfred Weber e depois cunhado por Karl Jaspers, que está no centro da análise $e^{5}$ A questáo fundamental é a seguinte: que fatores produziram esta revolução e como ela se desenvolveu nas culturas do mundo antigo, como em Israel, na Grécia, na China e na Índia? Quanto ao desenvolvimento do mundo moderno, de fato, Bellah quase nada nos informa. Apesar disso, no prefácio da obra temos uma observação importante. Segundo ele, alguns sugeriram que “[...] estamos no meio de uma segunda era axial, mas se assim é, deveria estar emergindo uma nova forma cultural. Talvez esteja cego, mas não a vejo. O que me parece que temos é uma crise de incoerência e uma necessidade de integrar, de maneira renovada, as dimensóes surgidas desde a era axial (BELLAH, 2011, p. xix).

Duas dessas proposiçóes me interessam diretamente: 1) Bellah acredita que após a era axial não surgiu nenhuma nova revolução das imagens do mundo; 2) e ele vê no presente uma crise cultural que acredita pode ser solucionada

5 Conferir também: Robert N. Bellah and Hans Joas (Eds.), The Axial Age and its Consequences (20/2). Livro que, por sinal, é dedicado a Karl Jaspers. 
com os recursos tradicionais da era pré-axial. Meu objetivo será questionar estas duas teses. Para solucionar esta crise, existem recursos que as culturas do mundo antigo não conheciam e, além disso, os recursos das religióes; mas, sejam quais forem, não são suficientes para que possamos superá-la.

Procederei em três passos. (1) Primeiramente, pretendo retomar o significado do conceito de era axial. (2) Em seguida, examino a tese da dissolução do religioso na era secular, bem como a autofundamentação dessa secularidade. (3) Por fim, farei a defesa desta autofundamentação contra a ideia de uma era pós-secular, além de questionar se a secularidade demanda ou não sua sacralização e, no caso afirmativo, de que forma.

\section{I $O$ que é uma cultura (era) secular?}

O debate sobre a era axial começou com Alfred Weber e Karl Jaspers e foi depois retomado e atualizado por Shmuel N. Eisenstadt. Portanto, a remissão que Robert Bellah faz a Karl Jaspers inscreve-se neste contexto intelectual (BELLAH, 2005, p. 69 ss) ${ }^{6}$. Vamos, pois, examiná-lo rapidamente.

Em 1935, Alfred Weber publicou, segundo ele próprio, o estudo de sua vida. Trata-se de uma pesquisa histórica intitulada Kulturgeschichte als Kultursoziologie, na qual vinha trabalhando desde 1931. O livro teve que ser publicado no exterior, pois não caía bem no contexto alemão da época (WEBER, 1997a) ${ }^{7}$. Neste escrito Alfred Weber desenvolveu a tese do desenvolvimento crescente de um terceiro homem, além de discutir o surgimento das "culturas avançadas primárias" e das "culturas secundárias do primeiro estágio". Aqui ele descreve a fisionomia cultural da China e da Índia e em particular das antigas culturas do oriente médio, desde as suas origens, passando pelos Judeus até chegar a Santo Agostinho. É neste contexto que ele fala de uma era mundial sincronizada. Na introdução da obra, na qual ele discute a construção da história, ele afirma:

Durante a segunda metade do período das grandes ondas de migração, entre os séculos 9 a 6 a.C., três esferas culturais em formação (a grega pré-asiática, a indiana e a chinesa)

\footnotetext{
Nesse contexto, também Eric Voegelin é constantemente mencionado.

7 A história de publicação do texto está descrita na introdução que Eberhard Demm (1997, p. 25 ss) escreve para as obras completas de Alfred Weber.
} 
foram levadas, com um grau de coincidência temporal notável, e aparentemente de forma independente, a se proporem questôes filosóficas e religiosas de alcance universal. A partir de Zoroastro, dos profetas judaicos, dos filósofos gregos, além de Buda, Lao Tsé e Confúcio, estas interpretaçóes filosóficas e religiosas de pensamento e ação sobre o mundo, em um processo contínuo de desenvolvimento e reformulaçáo (fossem elas inteiramente novas ou mesmo transformando-se e reformando-se em funçáo das influências mútuas) plasmaram o conteúdo de fé das religióes mundiais, bem como o substancial da interpretação filosófica da humanidade. Em termos religiosos, desde este período até o século XVI, nada de fundamentalmente novo apareceu na história. (WEBER, 1997a, p. 67 ss).

Portanto, não é com Alfred Weber que se origina a expressão "era axial”, ainda que a ideia já possa ser encontrada nele. O conceito, em si mesmo, foi formulado por Karl Jaspers (1983) que, em diálogo crítico com Alfred Weber, tomou distância da sua concepção, radicalizando a ideia de era mundial sincronizada. ${ }^{8}$ Jaspers aponta não apenas a simultaneidade no desenvolvimento destas três culturas, mas aponta especialmente sua interdependência. Ele destaca, em particular, a diferença entre as "culturas avançadas" e os "povos axiais": foram somente estes últimos que consolidaram esta ruptura, enquanto civilizaçôes como a Babilônica e Egípcia, bem como a China antiga e a cultura pré-indiana, pelo contrário, não o fizeram. Mas o que significa, aqui, ruptura? Trata-se de uma nova e radical compreensão da humanidade: à medida que o ser humano se torna consciente do ser como totalidade, "de si mesmo e de seus limites" ele também "experimenta o incondicional na profundeza de seu ser próprio e na clareza da transcendência” (WEBER, 1997a, p. 20). Jaspers afirma que esta mudança se deu no âmbito da reflexáo, ou seja, na consciência da própria consciência, ou, em seu conjunto, pela espiritualizaçáo e por uma nova forma de comunicabilidade: "É neste período que surgiram as categorias fundamentais que utilizamos ainda hoje e que se formaram as visóes religiosas que ainda influenciam a maior parte da humanidade" (WEBER, 1997a, p. 20). Pode-se também afirmar que, a partir história local, abriu-se a possibilidade da história mundial e o outro passou a ser observado não como um bárbaro, exótico ou inimigo, mas como um igual com o qual nós podemos aprender.

8 Para Jaspers (1983), Alfred Weber, além de Spengler e Toynbee são os principais autores que formularam uma "imagem autônoma da histórica" (p. 17). No entanto, Jasper critica a tese do surgimento simultâneo das grandes culturas como simplista, além de considerar a visão de Weber discutivel (p. 37). 
A era axial forja, segundo Jaspers, uma referência comum para o autoentendimento histórico. Ele situa a consolidação dessa era simultânea e interdependente de rupturas nas três culturas já nomeadas acima em torno do ano 500 a.C., ainda que o processo espiritual (cultural), como um todo, se estenda do ano 800 até ao ano 200 a.C. Neste ponto ele também se distancia de Alfred Weber, que data estes acontecimentos entre o século IX até o VI a.C. Mas, no que tange à sua caracterização geral, eles estão de acordo. Jaspers descreve a era axial de modo similar a Alfred Weber quando, por exemplo, assevera:

Neste período [entre os anos 200 a 800 antes de Cristo - acréscimo de Wolfgang Schluchter] muitas coisas extraordinárias aconteceram simultaneamente. Na China, na qual viviam Confúcio e Lao Tsé, surgiram praticamente todas as correntes da filosofia chinesa, incluindo Mo-Ti, Tschuang-Tse, Lie-Tse e inumeráveis outros. Na Índia aparecerem os Upanishades e, além de Buda, como na China, desenvolveram-se múltiplas posturas filosóficas, incluindo desde o ceticismo até ao materialismo, desde a sofística até ao nihilismo. Enquanto, no Irã, Zarathustra promovia a imagem da luta entre o bem e o mal, na Palestina surgiam os profetas Elias, Isaías e Jeremias, além do Deutero-Isaías e a Grécia via surgir Homero, os filósofos - Parmênides, Heráclito, Platão - e os Trágicos, além de Tucídides e Arquimedes. Tudo que a enumeração desses nomes nos sugere surgiu na China, na Índia e na Europa, em um período de tempo muito próximo entre si, e sem que elas estivessem relacionadas entre elas. (WEBER, 1997a, p. 20) ${ }^{9}$.

Frente a Alfred Weber, Jaspers alarga a duração da era axial, em compensação, limita sua duração apenas ao milênio antes de Cristo. Neste ponto, Shmuel N. Eisenstadt vai bem mais longe que os dois. Para começar, ele entende que o Cristianismo e o Islamismo também devem ser incluídos nas culturas axiais. De forma semelhante a Jaspers, ele também busca diferenciar aquelas culturas que, apesar de pressupostos favoráveis, não realizaram esta ruptura ${ }^{10}$. Ele também concorda com a ideia de que é na tensão crescente entre a ordem

9 A tese da era axial e também dos povos axiais tem como alvo principal a filosofia da história de Hegel, para o qual existe uma sequência evolutiva que começa com a China e termina com Roma e Grécia. Jaspers (1983, p. 30) nega essa visão evolucionista e afirma que ela não se sustenta "nem do ponto de vista temporal, nem lógico".

10 Kulturen der Achsenzeit. Ihre Ursprünge und ihre Vielfalt, Teil I, Griechenland, Israel, Mesopotamien, editado por Shmuel. N. Eisenstadt, Frankfurt a. M.: Suhrkamp 1987, em especial Allgemeine Einleitung, bem como Kulturen der Achsenzeit. Ihre Ursprünge und ihre Vielfalt, Teil 2, Spätantike, Indien, China, Islam, editado por Shmuel N. Eisenstadt, Frankfurt a. M.: I887, especialmente suas reflexões sobre as rupturas secundárias. 
imanente e a transcendente e na preponderância desta última que devemos procurar a marca decisiva da era axial. A institucionalização desta tensão, por sua vez, vem acompanhada de vastas transformaçóes sociais. Entre elas, a disputa entre elites religiosas e políticas e a luta destas últimas contra a ordem transcendental e seus representantes; a divisão das elites "religiosas" em ortodoxas e heterodoxas, o que, por sua vez, abre a possibilidade de novos movimentos de protesto; a reorganização do centro e a própria divisão entre centro e periferia da ordem política e social; a distinção entre tradiçóes religiosas majoritárias e minoritárias, a emergência do pensamento de segunda ordem e da categoria de história mundial e, por fim, a possibilidade de que rupturas secundárias [no interior da ruptura global] também ocorram. Pois é neste período que surgem os grandes textos sagrados que, ainda que canonizados e sacralizados, possibilitam sempre novas formas de leitura e interpretaçáo. Tudo isso engendra uma dinâmica cultural e institucional completamente desconhecida nas culturas da era pré-axial. "

No entanto, se na esteira de Eisenstadt, desejamos manter a tese da simultaneidade e interdependência das rupturas civilizacionais nestas três culturas, temos de diferenciar claramente entre eras (temporal) axiais e culturas axiais. O que há de comum entre estas diferentes culturas é o tipo de ruptura e não o ponto no tempo no qual ela ocorre. Daí que, em vez de era axial, seria muito mais adequado se falássemos em um princípio axial que as atravessa. Isso nos conduz para as seguintes indagaçóes: 1) o que seria este princípio e 2) existem também outros princípios?

Antes de respondê-las, é preciso qualificar ainda mais um detalhe. Até agora falei apenas de Robert Bellah, Alfred Weber e Shmuel N. Eisenstadt, mas não disse nada sobre Max Weber. Isto não é nenhum acaso, pois a perspectiva de análise sociológica da religião de Max Weber se enquadra muito limitadamente no conceito de era axial. Embora, em seus trabalhos filosóficos, Karl Jaspers (1985) não deixe de se orientar genericamente por Max Weber - em especial, no escrito de transição Die Psychologie der Weltanschauungen ${ }^{12}$

II Veja-se, em especial, a série Kulturen der Achsenzeit II. Ihre institutionelle und kulturelle Dynamik, parte I até a III, editada por Shmuel N. Eisenstadt, Frankfurt a. M.: Suhrkamp 1992.

12 Trata-se de um escrito de transição, ou seja, trata-se de uma passagem da psiquiatria para a filosofia. Na introdução a este esboço filosófico, ele diz o seguinte: "A sociologia da religião de Max Weber, bem como seus 
-, a abordagem de Weber diferencia-se da "estruturação da história mundial durante a era axial"13 em dois aspectos: (1) Para ele uma filosofia não tem o mesmo poder que uma religião de salvação para criar interiormente novas disposições de conduta; (2) e para ele nem a China e nem a Grécia foram marcadas por uma autêntica religiáo de salvação. Por essa razáo, Weber avalia o potencial transformador da cultura chinesa e grega de forma bem mais reservada que os teóricos da era axial (SCHLUCHTER, 2013, p. 1 ss). Em Weber a característica fundamental de era cultural também é a rejeição do mundo, mas ela é indissociável das religiōes de salvação.

Portanto, na perspectiva da sociologia da religião de Max Weber, existem fortes razóes que nos levam a colocar em dúvida o conceito de era axial. Por isso, entendo que a ideia de um princípio axial é um instrumento analítico muito mais útil para nos ajudar a pensar o que, apesar de suas diferentes fisionomias e épocas de surgimento, existe de comum nas culturas axiais. Curiosamente, é exatamente neste sentido, e isto apesar de não ter tido qualquer influência do debate sobre a era axial, que o conceito de princípio axial é utilizado pelo sociólogo americano Daniel Bell.

Em seu volumoso estudo, dividido em duas partes (The Coming of Post-Industrial Society, seguido de The Cultural Contradictions of Capitalism), ele menciona os princípios axiais que dominam os principais campos da sociedade moderna. Eles estão em contradição entre si o que desencadeia uma intensa dinâmica de conflito. Nas suas palavras: "O argumento elaborado neste livro é que as três esferas - economia, política e cultura - são governadas por princípios axiais opostos: para a economia, eficiência; para a política, igualdade; e para a cultura, autorrealização (ou autogratificação). As disjunçôes daí resultantes moldaram as tensões e os conflitos sociais da sociedade ocidental nos últimos 150 anos" (BELL, 1976, p. xi).

trabalhos políticos, contém um tipo de análise psicológica das visões de mundo completamente inovador em relação aos anteriores, pois ele relaciona algo que até agora não havia sido feito: pesquisa histórica concreta com pensamento sistemático. A força objetivo-sistemática que se manifesta nestes escritos não se congela em um sistema fechado, pois está associada com uma veemência vital que não vemos desde Nietzsche" (JASPERS, 1985, p. 14). Uma análise da relação entre Max Weber e Karl Jaspers pode ser encontrada na introdução de Dieter Henrich in: Karl Jaspers, Max Weber. Gesammelte Schriften, München: Piper 1988.

13 Tal como formulado por Jaspers (1983, p. 76). 
No entanto, para mim não se trata da disjunção dos campos (the disjunction of realms), mas do posicionamento do homem no mundo e dos princípios culturais que regem este posicionamento. Em minha análise, portanto, é o princípio axial, no sentido que lhe é dado pelos teóricos da era axial, ou mais precisamente, é o princípio cultural, que comporta formas de institucionalização diversas. A tese de Bell, que afirma que o princípio axial da sociedade moderna consiste na autorrealização, aponta neste sentido. Isso nos conduz para uma segunda indagação: existe, junto a este primeiro, também um segundo princípio axial? Essa questão também preocupava Karl Jaspers; afinal, além da ruptura que nos levou para a primeira era axial, ele visualizou ainda uma segunda ruptura - que denominou de "inigualável ruptura do Ocidente" - à qual atribuiu uma significação histórica de alcance universal. Até ao século 14, a Europa, a China e a Índia ainda se achavam no mesmo nível civilizacional, mas as extraordinárias transformaçóes culturais que aconteceram na Europa de 1500 a 1800 e que tiveram impacto no mundo inteiro trouxeram à tona a indagação por uma nova era axial (JASPERS, 1983, p. 102).

O próprio Karl Jaspers não estava convicto de que devêssemos falar de uma segunda era axial. Afinal, essa ruptura não era táo clara como a primeira, nem tinha o mesmo caráter dualista daquela. Todavia, apesar de concentrada na Europa, ele abria possibilidades que ainda se encontravam bloqueadas no período anterior. É especialmente na ciência e na técnica modernas que "[...] algo especificamente novo, fundamentalmente diferente do que encontramos no mundo asiático e até no mundo grego, se apresenta” (p. 104). São elas que, após tornar o mundo europeu, no decorrer do processo, também o tornaram antieuropeu. Ao final, Jaspers acaba se decidindo em favor da real possibilidade de uma segunda era axial, ainda que desloque essa possibilidade para o futuro, não para o presente (p. 128 ss). A ciência e a técnica modernas nos possibilitaram um domínio da natureza que não tem paralelo na história, mas acabaram produzindo a escravização da humanidade: "[...] existe o perigo de que o ser humano seja asfixiado pela segunda natureza que ele mesmo, a partir da técnica, criou, ainda que, em sua essência, ele até possa parecer relativamente livre em relação à natureza e ao seu eterno curso" (JASPERS, 1983, p. 129).

Jaspers (1983) parece, portanto, argumentar na mesma direção que Bellah, ou seja (e de acordo com a nossa terminologia), para ele é bastante claro 
que, pelo menos até agora, a modernidade ainda não representa um novo princípio axial. De fato, a maior parte do seu escrito (localizado no segundo volume), intitulado "Presente e Futuro", é fundamentalmente uma tentativa de nos fornecer uma resposta para esta questão: a modernidade é realmente algo novo ou são apenas os perigos que ela traz consigo que são novos (JASPER, 1983, p. 109 ss)? Esta mesma questão já incomodava Alfred Weber (1997b, p. 257 ss) que a colocou nos seguintes termos: o terceiro homem será sucedido pelo quarto homem?

\section{Secularidade: um novo princípio axial?}

Existem autores que defendem a tese de que os processos identificados por Jaspers em relação ao século XV europeu inauguraram uma nova etapa histórica: a era pós-secular, resultado do desencantamento do mundo. Um destes autores é Charles Taylor, para quem, no decorrer deste processo de desencantamento do mundo, não apenas o velho núcleo (podemos também dizer, o princípio axial) foi extirpado de suas ilusóes, mas também surgiu um núcleo inteiramente novo. Para ele, o desencantamento significa que as religiôes, anteriormente consideradas necessárias, tornaram-se apenas mais uma opção de vida entre outras. Ou seja, a referência ao transcendente, que tanto impressionou nossos teóricos da era axial, foi substituída pela referência ao imanente. A ela também está ligada uma nova forma de posicionamento do homem no mundo. Taylor (2012) denomina este posicionamento da era secular de Humanismo exclusivo.

Dessa maneira, Taylor (2012) retoma o controvertido debate sobre a secularização e lhe confere uma guinada filosófica. A secularização não é mais entendida como descristianização, nem como o desaparecimento da crença em Deus ou mesmo como continuidade das imagens religiosas do mundo por meios profanos ${ }^{14}$. Taylor evita contar uma "história da subtração" (p. 53), na

14 Taylor (2012, p. 15) distingue entre três sentidos do secular: I. como separação entre Estado e religião; 2. como declínio da prática religiosa; 3. como possibilidade da escolha religiosa. Fundamental é este terceiro significado: "Meu desejo é investigar nossa sociedade a partir desse terceiro significado de secular. Esse empreendimento poderia ser resumido da seguinte forma: esta mudança, que aqui quero compreender e determinar, diz respeito a transformação de uma sociedade na qual era praticamente impossivel não acreditar em Deus, para uma situação na qual esta crença, mesmo para pessoas religiosas, é apenas uma possibilidade entre tanta outras". 
medida em que procura os fundamentos intrínsecos de legitimação do secular. As principais diferenças estabelecidas pelo autor entre a imagem transcendente e a imagem imanente do mundo podem ser visualizadas a seguir:

Quadro I - Imagens de mundo

\begin{tabular}{|l|l|}
\hline Teodiceia & Antropodiceia \\
\hline Ênfase no criador & Ênfase na criatura \\
\hline O mal é de origem religiosa & O mal é de origem humana \\
\hline Pecado & Crueldade da ordem mundana \\
\hline Supramundana & Intramundana \\
\hline
\end{tabular}

Fonte: Adaptado de Taylor (2012, p. 899 ss).

Essa perspectiva nos remete logo à discussão sobre a "legitimidade dos tempos modernos", bem como a tese do desencantamento do mundo de Max Weber, que Taylor referencia diretamente. $\mathrm{Na}$ verdade, ambas as visôes não são exatamente idênticas, como pretendo mostrar a seguir.

Em suas origens, secularização era um conceito político, mas ele foi neutralizado para ser utilizado como categoria de análise de processos de transformação de larga escala. ${ }^{15}$ Dessa forma, podemos distinguir entre um conceito filosófico e um conceito histórico-empírico de secularização, e, neste último caso, entre um conceito que se refere à imagem de mundo, às instituições (poder político ou hierocrático) ou às mentalidades (SCHLUCHTER, 1988, p. 506 ss). Na perspectiva da filosofia sempre permaneceu polêmico se a secularização, conforme a terminologia de Charles Taylor, deveria ser compreendida como uma categoria de subtração ou se ela deveria ser compreendida como um modo pelo qual podemos fundamentar a legitimidade dos tempos modernos. Na primeira posição encontramos a obra de Carl Schmitt (2009 [1922]) com suas teses sobre a teologia política, bem como Karl Löwith (1983 [1949]), com seu extraordinário estudo sobre a relação entre história sagrada e história secular. A segunda posição é defendida por Hans Blumenberg (1974).

15 Os diferentes significados do conceito de secularização são discutidos com especial pertinência por Hermann Lübbe em Säkularisierung. Geschichte eines ideenpolitischen Begriffs, Freiburg/München: Karl Albers, 1965. 
Para Carl Schmitt (2009 [1922], p. 41 ss), os principais conceitos da teoria política são conceitos secularizados e estão diretamente relacionados com a transição da imagem transcendente para a imagem imanente do mundo, processo que se consolidou nos séculos XVIII e XIX. Löwith, por sua vez, mostra que a filosofia da história pode ser compreendida como uma secularização da fé cristã na qual, como sabemos, o crente está confrontado com uma radical tensão entre o presente e o futuro. Isto porque, para o cristão, a realização plena da vida iniciou-se no presente com Jesus Cristo, mas sua consumaçáo através do julgamento dos justos somente se realizará no futuro. Esse fato nos leva para uma "profunda ambiguidade do cumprimento histórico", pois "o ser humano ainda tem fé e confia", alegrando-se de "forma confiante por aquilo que ansiosamente aguarda” (LÖWITH, 1983 [1949], p. 201). Essa história da salvação, uma vez secularizada, desemboca nas filosofias teleológicas da história. ${ }^{16} \mathrm{O}$ próprio Löwith está convencido de que a história secular não deve ser compreendida dessa forma, pois ela não pode ser lida nem pelas cosmologias antigas, nem pela teologia cristã. Não existe uma história cristã, motivo pelo qual também não podemos falar de uma secularização dessa história: "[...] o mundo pós-cristão é uma criação sem criador, um saeculum que, dada a falta de uma perspectiva religiosa, mais do que profano é, no fundo, apenas mundano" (LÖWITH, 1983 [1949], p. 216).

Hans Blumenberg opóem-se tanto a Carl Schmitt quanto a Karl Löwith. Ele critica o fato de que os dois, ainda que cada um à sua maneira, interpretem a consciência histórica da modernidade com categorias substancialistas. Para ele, o teorema da secularização, em qualquer uma de suas versôes,

I6 De acordo com Löwith, podemos identificar três grandes imagens históricas: a cosmológica, segundo a qual o Universo é divino e eterno (teologia natural); a teológica, segundo a qual o Universo foi criado por Deus e é transitório (teologia sobrenatural) e a histórica: o mundo foi criado pelo ser humano e é transitório (antropologia natural ou teleologia do progresso). A posição defendida por Löwith fica bastante clara na seguinte passagem: "o ser humano é o único dos seres que, na medida em que a própria natureza o permite, pode cultivar, transmitir ou mesmo negar sua própria natureza. Nós somos natureza e seres históricos e, por esse motivo, podemos compreender tanto a uma como a outra, no entanto ambas não pertencemos a elas de modo similar, pois quando cultivamos a natureza, agimos historicamente e incluímos a natureza em nosso mundo, já deixamos, enquanto seres dotados desta capacidade de agir, a história natural. Quando deixamos de compreender a natureza como uma realidade criada por Deus para o ser humano, isso significa que ela não estava destinada a trazer o ser humano ao mundo e que ela continuará a existir mesmo que não exista mais nenhum ser humano, sem que esse fim da história tenha qualquer significado histórico para a própria natureza" (LÖWITH, 1983 [1949], p. 329). 
é "[...] uma forma de substancialismo histórico, pois seu substrato teórico depende da comprovação de fatos históricos entendidos como constantes" (BLUMENBERG, 1974, p. 35 ss). ${ }^{17}$ Interpretar a modernidade como secularizada (independentemente do que isso possa significar) é entendê-la de modo completamente equivocado, pois implica assumir uma identidade substancial entre a origem e o resultado. A legitimação dos tempos modernos não pode ser pensada como uma mera transferência [Umsetzung] do que já se encontrava disponível, tratando-se, ao contrário, de uma reocupação [Umbesetzung] ${ }^{18}$. Para Blumenberg a ruptura entre o passado e os tempos modernos é absolutamente radical e o conceito de secularização não nos permite enxergar isso, seja normativa, seja descritivamente: se a modernidade, quanto à sua existência histórica, fosse secularizada, seria "apenas a personificação daquilo que ela, de fato, não deveria ser" (BLUMENBERG, 1974, p. 136). Ademais: "[...] com a categoria secularização temos que reconhecer, ou pelo menos deveríamos reconhecer de forma consequente, que a modernidade é uma época original, ainda que possamos discutir até que ponto a autenticidade que, fundada na razão, ela reclama de si mesma, resulta realmente de suas próprias forças" (BLUMENBERG, 1974, p. 143).

Se a modernidade quer legitimar-se a partir de si mesma, então precisamos postular para ela um novo princípio axial. Seguindo o debate sobre a secularização, além das objeçóes feitas por Blumenberg, podemos ver este novo princípio axial na mundanização da realidade, ou seja, em sua imanentização. É claro que náo existe nenhum presente sem algum grau de continuidade com o passado. No entanto, esta mundanização ou imanentização não pode ser reduzida a uma categoria do desaparecimento que aponta apenas para o declínio da religião. Bem ao contrário disso, ela é uma categoria de direito próprio. Se o signo da primeira era axial foi a transcendentalização, então o signo dos tempos podermos somente pode ser a imanentização: a transformação da teodiceia em antropodiceia.

17 Sobre o confronto com Carl Schmitt e Karl Löwith sobre Blumenberg (1974, p. 106 ss, 35 ss, respetivamente).

18 Blumenberg enfatiza que a mundanização do mundo representa, além de sua conquista, também a perda do mundo. A secularização não deve ser descrita como uma transferência de conteúdos teológicos para a esfera mundana, mas sim como a re-ocupação de uma posição que ficou vazia, pois as perguntas que movem os seres humanos não podem ser simplesmente eliminadas (BLUMENBERG, 1974, p. 77). 
Combinando o esquema de Blumenberg ${ }^{19}$ com a proposta de Charles Taylor vemos que o ponto decisivo na transição para a era secular não está no declínio da religião, mas no fato de que ela se tornou opcional. Não é que na era secular a religião simplesmente desaparece. A questão é que ela vai se tornando, paulatinamente, objeto de escolha, permitindo-nos não apenas optar entre religiôes distintas (ou mesmo entre as confissôes de uma mesma religião), mas também decidir entre ser religioso ou não religioso. Esse aspecto não foi inteiramente captado pelo clássico conceito de secularização. Por isso Taylor, com toda razão, prefere remeter-se ao conceito weberiano de desencantamento do mundo.

No entanto, em Weber o conceito de desencantamento do mundo tem um sentido muito mais complexo do que na adaptação feita por Taylor. Para começar, para ele o desencantamento não começa no século XVI, mas já na era axial. O desencantamento descreve um processo que se inicia no judaísmo antigo e no mundo helênico e que, em diferentes estaçóes, desenvolve-se no interior do cristianismo, atingindo seu ponto máximo no protestantismo ascético do século XVII. ${ }^{20}$ Por um lado, Weber entende este conceito como um processo impulsionado religiosamente que conduz à desmagificação dos caminhos de salvação. O resultado é uma total interiorização da fé, tendo em vista que entre Deus e os homens não existe mais nenhuma instância intermediária (WEBER, 1920, p. 464 ss). Por outro lado, o processo de desencantamento acaba indo mais longe do que aquele impulsionado pela religiáo, tornando-se, assim, um processo conduzido pela ciência. ${ }^{21}$ Em consequência disso, o lugar da religião no conjunto das esferas de valor e das ordens de vida se altera. Ambos os processos não são, naturalmente, independentes um do outro, mas durante muito tempo eles se restringiram mutuamente.

19 Na segunda parte do escrito denominado Theologischer Absolutismus und humane Selbstbehauptung, Blumenberg (1974, p. 144 e 165) afirma que a modernidade representa uma segunda superação do gnosticismo: "A Gnose tornou o problema da qualidade do mundo para o ser o humano ainda mais agudo e, em oposição a patrística e ao pensamento medieval, que a combateram, plantou as bases de uma teodiceia entendida como cosmodiceia. A modernidade, por sua vez, recusou-a, na medida em que fundamentou a antropodiceia na crueldade do mundo frente ao ser humano, ou seja, em sua ordem desumana".

20 Segundo Max Weber (1920, p. 513), é apenas no puritanismo que um radical desencantamento do mundo foi levado até as suas últimas consequências.

2I Para mais detalhes, ver Schluchter (2009), especialmente o capitulo I. Veja-se também minha introdução em Weber (1920). 
Atualmente, com a mudança no quadro de referência, no sentido de Taylor, tanto a religiáo como a ciência tornaram-se potências crescentemente opostas. $\mathrm{Na}$ sua Consideração Intermediária, Weber descreve este conflito de forma bastante nítida, observando:

Ali onde o conhecimento empírico-racional realizou de modo mais consequente o desencantamento do mundo e sua transformaçáo em um mecanismo causal, surge uma tensão contra as pretensōes de um postulado racional: a de que o mundo seja um cosmos divinamente ordenado, ou seja, um cosmos pleno de significado ético. Pois a observaçáo de orientação empírica e totalmente matematizada do mundo desenvolvem, por princípio, uma rejeição a toda forma de consideração que, de alguma forma, indaga sobre o "sentido" dos acontecimentos intramundanos. A cada avanço do racionalismo empírico da ciência, a religiáo vai sendo paulatinamente deslocada do reino do racional para o irracional, tornando-se o poder suprapessoal, anti-racional $[s i c]$ e irracional por excelência [...].

E ele acrescenta: "O grau de consciência ou de ação consequente que resultam dessas oposiçóes é inteiramente diverso” (WEBER, 1920, p. 479 ss) -, sem contar o fato de que o conflito entre fé e razão não é, de resto, um fenômeno exclusivamente moderno.

Logo, Charles Taylor não utiliza o conceito de desencantamento do mundo no sentido de Max Weber, o que não quer dizer, é claro, que não existam concordâncias. A mais importante é a tese de Taylor que afirma que no século $\mathrm{XV}$ a religiáo (ainda) era considerada uma necessidade: a liberdade em relação à religião ainda não existia. Max Weber faz uma constatação parecida no seu estudo A ética protestante e o espírito do capitalismo ao afirmar que, atualmente, não conseguimos mais imaginar como as questóes religiosas eram realmente importantes para os indivíduos do século XVII ${ }^{22}$. Weber se refere ao sentido subjetivo da ação, mas o fato é que no plano objetivo o indivíduo não tinha outra opçáo. Essa situação foi mudando à medida que a liberdade religiosa foi se tornando um direito constitucional, sem esquecer, é claro, da importância do pluralismo religioso que foi se desenvolvendo na Europa a partir da

22 Conforme Max Weber (2014, p. 270 ss, p. 366 ss): "Em uma época em que o além era tudo, em que posição social do cristão se media pela possibilidade de participar da celebração da comunhão e a influência do sacerdote através do acompanhamento espiritual, da disciplina religiosa e da pregação, era de uma importância, que nós, homens modernos, sequer conseguimos imaginar, uma simples vista de olhos sobre as coletâneas de 'consilia', 'casus conscientiae' etc., nos mostra que os poderes religiosos que se exprimem nessa práxis são os elementos decisivos que moldam o caráter de um povo". 
Reforma. No século XIX, a pluralização da cena religiosa e o desenvolvimento jurídico já tinham progredido de tal forma que, pelo menos nos meios religiosos mais heterogêneos, já reinava ampla liberdade religiosa. Como constatou Rudolf Schlögl (2013, p. 248), no seu extraordinário estudo sobre as rupturas na cristandade europeia entre 1750 e 1850 , “[...] o sistema religioso passou a oferecer a possibilidade de confissôes e denominaçóes alternativas, do sincretismo e, mais importante que tudo, tornou indiscutível a possibilidade de que viver sem religiáo significasse, de imediato, exclusão social”. No entanto, também é claro que em ambientes religiosos mais homogêneos ainda persistiam, apesar das garantias legais, mecanismos de exclusão social. Hoje, por fim, tendo em vista o contexto imanente de referência, a cena religiosa assemelha-se a um mercado no qual as comunidades religiosas disputam fiéis da mesma forma que, na esfera econômica, vendedores competem pelos seus clientes (GRAF, 2004).

Historicamente, o conceito de secularização vem associado à mudança na relação institucional entre religiáo e política que acompanha a progressiva formação do Estado-Nação. ${ }^{23} \mathrm{O}$ declínio da aristocracia social significa também o declínio da aristocracia religiosa; já para a Igreja Católica, em particular, a Revolução Francesa significou não apenas a secularização de seus bens, mas acima de tudo a secularização de seu poder político (SCHLÖGL, 2013, p. 107). O conceito weberiano de desencantamento também abarca essa dimensão, pois à medida que este processo se consolida, não é apenas a mentalidade ou imagem de mundo que se altera, mas também a ordem institucional ${ }^{24}$. A tese da mudança do quadro de referência de Charles Taylor expressa esse aspecto muito bem.

De toda forma, seria um equívoco caso apresentássemos a era das religióes como se ela fosse completamente uniforme e a era secular, ao contrário, como

23 Genericamente, associa-se secularização como a expropriação dos bens da lgreja, tal como afirma, por exemplo, o verbete do dicionário abaixo: 'Secularização (do latim saeculum 'temporal', 'mundano' ou também, 'paganismo') refere-se a expropriação, pelo poder temporal (príncipes, revolucionários, etc.), e sem o consentimento eclesiástico, de bens e propriedades que pertenciam ou eram administrados pela Igreja (ordens religiosas, etc.) ocorrida na França como resultado da revolução francesa, na Alemanha desde 1893/04 e na Itália desde 1870, novamente na França a partir de 1893/04 e na Rússia antes e depois da revolução de Outubro de 1917". V. Kleines Lexikon des Mönchtums. Johanna Lanczkowski, Stuttgart: Philipp Reclam, jun. 1993, p. 220.

24 Uma descristianização institucional supõe, naturalmente, a descristianização mental (SCHLÖGL, 2013, p.I I5 ss). 
inteiramente pluralista. Também a era religiosa tinha a sua diversidade, se analisarmos as diferentes civilizaçóes ou se observamos a diversidade existente no seio das grandes religióes mundiais ${ }^{25}$. O que diferencia, em última instância, o quadro de referência transcendente do imanente é o fato de que, neste último, é possível escolher uma religião, mas esta não é uma escolha obrigatória. Além disso - independentemente da opção desejada -, nem uma, nem outra trazem prejuízo a ninguém. No seu sentido mais amplo, a liberdade religiosa significa não apenas que não precisamos viver sob o jugo de uma única religião mas também que temos o direito de escolher viver sem ela. Trata-se de uma conquista tardia da era secular e ela pressupóe que a religiáo tenha sido deslocada definitivamente para segundo plano da vida sociocultural e que a comunidade jurídico-política não seja regulada religiosamente.

Esse deslocamento da religiáo para o segundo plano da ordem social pode ser observado a partir da história da liberdade religiosa. A organização dos grupos cristãos na forma de confissóes (católica e protestante), motivada pela Reforma, bem como a experiência das guerras religiosas, logo obrigaram a Europa a reconhecer a importância da tolerância religiosa. Estudando o tema a partir do caso alemáo, o jurista Horst Dreier (2013) observou atentamente os passos iniciais que desembocaram, por fim, na formulação do parágrafo 1 do artigo $1^{\circ}$ da Constituição da República Federal da Alemanha, que assim dispóe: "A liberdade de crença, de consciência e de visão ideológica são invioláveis.” E este não é apenas um princípio jurídico de caráter programático, mas um direito imediatamente válido.

Este artigo é o resultado de um longo processo de desenvolvimento, cuja estação inicial foi o Tratado de paz de Augsburgo, de 1555. Neste caso, contudo, ainda não se tratava da liberdade de crença dos súditos, mas apenas das suas obrigações: Obrigkeit (cuius Regio, eius Religio). Por essa razão, Dreier fala que ela estabeleceu somente a dualidade de crença entre católicos e protestantes. A situação se alterou apenas com o Tratado de Vestefália, quando a liberdade de crença foi ampliada, incluindo católicos, protestantes e os demais reformados. As demais estaçóes deste desenvolvimento que, segundo Dreier, incluem o Código Civil prussiano de 1794, a Constituição de 1848 e a

25 Conforme citação acima. 
Constituição da República de Weimar (1919), estabeleceram novas relaçôes entre o Estado e a religião. Ela engloba três componentes: a separação entre Estado e Igreja (ainda que na Alemanha ela não seja táo consequente como nos EUA ou na França); a liberdade de crença e de pensamento (no seu sentido mais amplo, o que inclui a mais ampla liberdade para a prática religiosa); bem como a separação dos fundamentos do direito de qualquer religiáo ou visão de mundo (DREIER, 2013, p. 12 ss).

De fato, seria um erro fatal se o Estado secular se colocasse no lugar da religião e assumisse qualquer tipo de visão de mundo. Como observou corretamente Horst Dreier, o Estado secular não pode ser considerado o guardião do plano da salvaçáo e nem pode responder as questóes sobre a verdade e o sentido da existência. Ele não representa um substituto [Ersatz] para as cosmovisóes religiosas, ainda que lhes ofereça uma plataforma (DREIER, 2013, p. 38). Ele deve assumir uma postura neutra em relação a qualquer religião ou visão de mundo, ainda que, como imaginam muitos, possamos contar com a volta dos deuses (DREIER, 2013, p. 112). Isso nos leva para nossa última questâo que indaga se, mesmo em um Estado neutro do ponto de vista valorativo, não se encontra uma forma de secularidade que acaba extrapolando a neutralidade em relação às religiôes e visôes de mundo.

\section{Sacralizalização da secularidade?}

A Constituição da República Federal da Alemanha começa com um preâmbulo que faz referência a Deus e com o famoso $\$ 1$ que menciona que "a dignidade humana é inviolável"26 Aqui podemos visualizar todos os fundamentos jurídicos que transcendem a Constituição. Portanto, o Estado secular parece fundamentado em algo que, em si mesmo, não parece tão secular, mas sim religioso, dado que a dignidade humana é um produto do cristianismo. Assim, a autofundamentação da modernidade parece negada e suas pretensôes de legitimidade soam ilusórias.

Essa tese é veementemente negada por Horst Dreier que, neste ponto, segue de perto as ideias de Hans Blumenberg e sua tese de que a secularização

26 A redação completa desse artigo é a seguinte: “A dignidade humana é inviolável. É dever do Estado respeitá-la e protegê-la. 
é uma categoria da ilegitimidade histórica. Isso não significa que o cristianismo não tenha contribuído para a gênese da moderna ordem legal. No entanto, a dignidade humana não pode ser considerada uma "sacralização das crenças cristãs” (DREIER, 2013, p. 87), seja porque ela também possui outras fontes que não são religiosas (e com as quais, muitas vezes, ela contrasta), seja ainda porque devemos distinguir entre gênese e validade: "o fundamento religioso foi substituído pela produção de normas do Estado secular" (DREIER, 2013, p. 49) ${ }^{27}$.

De qualquer forma, os protagonistas da Revolução Francesa não se contentaram apenas com a descristianização da vida social. Eles procuraram criar um fundamento sagrado de caráter não religioso para esta nova ordem secular, e isto na forma de uma cultura da razão e de um culto do "ser soberano", incluindo até santos. Os revolucionários acabaram fracassando, mas o seu ideal permaneceu atrativo (SCHLÖGL, 2013, p. 118 ss). Dentre os que ajudaram a formular tais ideias, ainda que de modo independente dos esforços revolucionários, podemos lembrar o sociólogo francês Émile Durkheim que associou a secularidade com o culto do indivíduo e propôs sua institucionalização na forma de uma religião civil.

Durkheim também assume que entre o passado e o presente ocorreu um corte radical e, acompanhando Taylor, visualiza uma mudança em nossos quadros de referência, deslocando a ênfase dos ideais coletivos para os valores individuais. Ele explica que essa mudança nas representaçóes (passagem do coletivismo para o individualismo ou do culto ao grupo para o culto ao indivíduo) veio acompanhada também por uma mudança nas formas de pensamento e de ação: do pensamento heterônomo para o autônomo, do religioso para o secular, ou, como diz ele na linguagem francesa pós-revolução: pela moral laica ${ }^{28}$. Logo, não é nada casual que Charles Taylor (2002, p. 57 ss), quando reflete sobre as consequências que a mudança em nossos quadros de referên-

27 Para analisar o surgimento dos direitos humanos, veja-se Georg Jellinek, Die Erklärung der Menschen- und Bürgerrechte. Ein Beitrag zur modernen Verfassungsgeschichte, Leipzig: Duncker E Humblot 1895. Atualmente, o assunto é tratado por Hans Joas em Die Sakralität der Person, Frankfurt a. M.: Suhrkamp 20 II. Na linha de Ernst Troeltsch, Jonas defende um método genealógico afirmativo que não diferencia juizos causais de juizos valorativos e não diferencia entre a gênese e a validade.

28 Com maiores detalhes em Wolfgang Schluchter, Grundlegungen der Soziologie, Band I, Tübingen: Mohr Siebeck, 2009. 
cia, produziu na relação entre religião e política, ou entre Igreja e Estado, sirva-se de Durkheim: ele menciona formas paleo, neo e pós-durkheimianas de relação entre religião e Estado.

Mas não devemos ler Durkheim como se a sua luta por uma religiáo civil, na qual ele se remete a Jean Jacques Rousseau (que, por sua vez, também inspirou Robert Bellah), representasse a tentativa de fundar um culto estatal, uma espécie de religião substitutiva [Ersatzreligion] cujo propósito é satisfazer a necessidade humana de referência ao sagrado com o auxílio do Estado. No centro da sua proposta de religiáo civil não se encontra o Estado, mas a personne humaine. O Estado só adquire traços sagrados na medida em que ele observa e faz observar os direitos humanos, cuidando para que eles possam ser aplicados especialmente a grupos particulares. A religiáo civil de Durkheim deve ser compreendida como uma forma de individualismo cognitivo e moral no qual o ideal a ser venerado é o ser humano, e não o Estado (TAYLOR, 2002, p. 189 ss).

Entretanto, na religião civil reside indiscutivelmente um elemento sagrado e esta sacralização da personne humaine tem sua origem na sociedade, ao mesmo tempo em que lhe serve de fundamento. Ela precisa velar para que os direitos e deveres particulares náo entrem em contradição com os direitos e deveres universais. É neste ponto que, segundo Durkheim, reside o núcleo da religião civil. Este núcleo, por outro lado, varia de acordo com a história das sociedades nacionais. Comparando os Estados das naçôes Ocidentais, nas quais a ideia de um Estado neutro frente a qualquer religião ou visão de mundo está institucionalizada, constatamos que, apesar disso, existem diferenças muito marcantes. Elas variam desde a conotação religiosa dos EUA como a Nova Jerusalém (BELLAH, 1970, p. 168 ss), passando pela Gloire da Grande Nation na França, sem esquecer ainda do patriotismo constitucional da República Federal da Alemanha.

Não resta dúvida de que Durkheim tende a interpretar a autotranscendência do ser humano (no contexto de uma imagem imanente de mundo) como resultado de novos ideais coletivos de caráter coercitivo. Contudo, esta não é uma ideia que precisamos aceitar, o que nos leva de volta para Max Weber e Karl Jaspers. Dessa forma, percebe-se que um dos desafios fundamentais da primeira era axial consistiu em personificar o distante e onipotente 
Transcendente, tornando-o mais próximo do ser humano, ou seja, o desafio consistia em imanentizá-lo. O desafio da segunda era axial, por outro lado, é transcender a imanência mas não através de uma ordem moral coletiva, e sim através de uma moralidade individual.

Para Weber (1920, p. 40 ss), esse problema é formulado em termos da conduta de vida em um mundo desencantado, desafio que ele soluciona pelo apelo a um individualismo heroico. Para Karl Jaspers (1983, p. 187), tratava-se da preocupação com a humanidade após a barbárie nacional-socialista. Ao refletir sobre a possibilidade de uma segunda era axial após a experiência dessa "sombria e iníqua desumanidade”, ele tinha a esperança de que, apesar de tudo, a humanidade não estivesse perdida: "ela não é regida apenas por instintos ou mesmo apenas pela razão, pois possui uma natureza que vai além de si mesma”. Ela pode tornar sua parte desta vastidáo que a ultrapassa e, dessa forma, tornar-se ela mesmo. "Podemos chamá-la de Ideia, na medida em que o ser humano é espírito, ou podemos chamá-la de Fé, na medida em que ele é existência” (JASPER, 1983, p. 269). No entanto, a necessidade e possibilidade para a autotranscendência em nossa era secular não depende mais do vínculo com a religião.

Não resta dúvida de que, mesmo em nossa era secular, com seu quadro de referência imanente, o dilema religioso ainda não foi resolvido, ainda que, como já vimos com Taylor, a religião tenha deixado de ser uma necessidade. Cada um pode viver sem religiáo e é exatamente contra isso que o fundamentalismo, existente em todas as religióes, parece se revoltar. Ocorre que o fundamentalismo religioso não pode ser compreendido apenas como retorno aos fundamentos imutáveis da religiáo, a uma leitura literal de escritos sagrados e canonizados, ou mesmo apenas como uma forma de impor valores absolutos por meios modernos ${ }^{29}$. Trata-se, acima de tudo, de uma luta contra a ideia de que a religião se tornou opcional e que, por isso, ela deva concorrer tanto com outras religióes quanto com o náo religioso. Entendendo o fundamentalismo dessa forma, compreendemos que ele nos exige o "sacrifício do intelecto" (WEBER, 1920, p. 110).

Por fim, voltemo-nos novamente para Robert Bellah, com quem iniciamos as nossas reflexóes: afinal, existe ou não uma segunda era axial? Se tomarmos

29 V. também Shmuel N. Eisenstadt, Die Antinomien der Moderne, Frankfurt a. M.: Suhrkamp 1998. 
como critério os elementos que determinaram o que foi a primeira era axial, ou seja, a simultaneidade temporal e a independência de processos de desenvolvimento que, em diferentes parte do mundo, seguiram uma direção similar, nossa resposta teria que ser negativa. Como já observou Karl Jaspers, a era moderna, com seu quadro de referência imanente é, no final das contas, um produto ocidental-europeu que, seja pela via pacífica, seja através da guerra, acabou se tornando um fenômeno mundial. O desencantamento do mundo, conforme a compreensão de Max Weber (1920, p. 11), foi um fenômeno ocidental que nos legou "o racionalismo específico da cultura ocidental".

A multiplicidade da modernidade, como afirma Shmuel N. Eisenstadt, possui um caráter diferente da diversidade de culturas e civilizaçôes da primeira era axial, pois ela não é resultado de desenvolvimentos paralelos e, em parte, também é fruto de uma luta contra a forma específica de racionalismo da cultura ocidental. Não obstante, esta luta somente é possível nos marcos do princípio axial moderno, pois mesmo aquelas variaçóes da modernidade que se voltam contra a Europa e o Ocidente o fazem, caso desejem modernizar-se, adotando como pano de fundo uma visão imanente do mundo. No entanto, ao contrário do que supunha Bellah, o princípio axial da imanência náo implica a supressão do dualismo. Não se trata de um dualismo que introduz a transcendência na imanência, mas que, ao contrário, nos conduz da imanência para a transcendência, ou melhor, para a autotranscendência, no sentido de Karl Jaspers. Tal é a nova constelação que nos foi trazida pela civilização técnico-científica ocidental e que, mesmo no caso de um suposto retorno dos deuses, não nos levará em direção a nenhuma era pós-secular. ${ }^{30}$

\section{Referências}

BELL, D. The Cultural Contradictions of Capitalism. Nova Iorque: Basic Books, 1976.

BELLAH, R. Beyond Belief. Essays on Religion in a Post-Traditional World. Nova Iorque: Harper \& Row, 1970.

30 Em vez de secularização, Horts Draier (2013, p. 73) prefere falar em mudança de constelação. A metáfora do retorno dos deuses é constantemente atribuida à Max Weber. No entanto, sua alocução em Ciência como profissão não deve ser compreendida de forma reducionista, pois os antigos deuses que retornam de seus túmulos para retomar sua eterna luta não reaparecem enquanto divindades, mas como poderes impessoais. 
What is axial about the axial age?. European Journal of Sociology, v. 46, n. 1, p. 69-87, 2005.

Religion in human evolution: from the Paleolitic to the Axial Age. Cambridge, Mass: Belknap Press of Harvard University Press, 2011.

.; HANS J. (Ed.). The Axial Age and its Consequences. Cambridge, Mass.: Belknap Press of Harvard University Press 2012.

BLUMENBERG, H. Säkularisierung und Selbstbehauptung. Erweiterte und überarbeitete Neuausgabe von "Die Legitimität der Neuzeit”, erster und zweiter Teil. Frankfurt a. M.: Suhrkamp, 1974.

DREIER, H. Säkularisierung und Sakralität. Tübingen: Mohr Siebeck, 2013.

GEERTZ, C. Religion as a Cultural System. In: The Interpretation of Cultures: Selected Essays by Cliffford Geertz. Nova Iorque: Basic Books, 1973.

GRAF, F. W. Die Wiederkehr der Götter. Religion in der modernen Kultur. Munique: C. H. Beck, 2004.

JASPERS, K. Vom Ursprung und Ziel der Geschichte. 8. ed. Munique: Piper, 1983.

Psychologie der Weltanschauungen. 6. ed. Munique: Piper, 1985.

LÖWITH, K. [1949]. Weltgeschichte und Heilsgeschehen. Zur Kritik der Geschichtsphilosophie. Sämtliche Schriften 2. Estugarda: J. B. Metzlersche Verlagsbuchhandlung, 1983.

SCHLUCHTER, W. On the Place of the Study on Confucianism in Max Weber's Work. Taiwan Journal of East Asian Studies, v. 10, n. 2, p. 1-32, dec. 2013.

Religion und Lebensführung. Frankfurt a. M.: Suhrkamp, 1988. v. 2.

. Die Entzauberung der Welt. Sechs Studien zu Max Weber. Tübingen: Mohr Siebeck, 2009.

SCHLÖGL, R. Alter Glaube und moderne Welt. Europäisches Christentum im Umbruch 1750-1850, Frankfurt a. M.: S. Fischer, 2013.

SCHMITT, C. Politische Theologie. Vier Kapitel zur Lehre von der Souveränität. 9. ed. Berlim: Duncker \& Humblot, 2009 [1922].

TAYLOR, C. Die Formen des Religiösem in der Gegenwart. Frankfurt a. M.: Suhrkamp, 2002. Ein säkulares Zeitalter. Frankfurt a. M.: Suhrkamp, 2012. 
WEBER, A. Kulturgeschichte als Kultursoziologie. Alfred Weber-Gesamtausgabe, Band 1. Introdução de Eberhard Demm (Ed.). Marburg: Metropolis-Verlag, 1997a.

Der dritte oder der vierte Mensch. In: BRÄU, R. (Org.). Vom Sinn des geschichtlichen

Daseins. Alfred Weber-Gesamtausgabe, v. 3, Marburg: Metropolis Verlag, $1997 \mathrm{~b}$.

WEBER, M. Gesammelte Aufsätze zur Religionssoziologie I. Tübingen: J.C.B. Mohr (Paul Siebeck), 1920.

Asketischer Protestantismus und Kapitalismus. SCHLUCHTER, V.; BUBE, U. (Org.).

Schriften und Reden 1904-1911. Tübingen: J.C.B. Mohr (Paul Siebeck), 2014.

\section{Modernity: A new axial (era) culture?}

\section{Abstract}

The proposition of an axial age, lasting roughly from 800 to 200 B.C. and occurring in major civilizations (China, India, Near East) independent of each other, first introduced by Alfred Weber and Karl Jaspers, then further developed by Robert Bellah and S. N. Eisenstadt among others, implied from the outset the question whether there has been a second axial age, leading to modernity, and if so, whether this second axial age consists in a secularization of the achievements of the first axial age. In this article it is argued that the notion of a second axial age is meaningful, but that the emergence of modernity canst be accounted for in terms of secularization of the achievements of the first axial age. Rather, a new axial principle was institutionalized which separates the modern from the premodern world. This new principle is spelled out with reference to Hans Blumenberg, Charles Taylor and especially Max Weber. The emphasis is on the dialectics of disenchantment and the place of religion in a secular age.

Keywords: First and second axial principle. Dialectics of disenchantment. Religion in a secular age. 